appreciated. Dr. John Ellis, the leading British medical educationalist, in a masterly paper entitled 'The Choice of Remedy', makes very clear the impossibility and the futility of trying to teach the medical student all that is known in all branches of medicine and the vital importance of using the undergraduate years to develop the mind of the doctor so that he may take full advantage of future advances in medical knowledge and so that he can easily assimilate postgraduate vocational training for whatever sphere of medicine he may choose as his life's work. Professor Richard Scott, the new Professor of General Practice in the University of Edinburgh, contributes a splendid paper on the work of the general practitioner in the community which should be read by all who consider this to be their metier.

Excellent sections on the importance of the basic sciences, psychology, psychiatry and social medicine in the preparation of the doctor for his work in the community are included and the final paper by Dr. Hobson from the World Health Organisation is outoutstanding. Dr. Hobson reviews the world-wide effect on medical education of the Flexner and Goodenough reports, the work in this field that has been done at Western Reserve University, and the contribution of the Association for the Study of Medical Education and of the World Health Organization itself.

\section{Textbook of Abnormal Psychology}

N. H. Pronko, Ph.D. Pp. xxii +446 , illustrated. Baltimore: Williams \& Wilkins. London: Baillière, Tindall \& Cox. I963. 68s.

Professor Pronko, who is Head of the Department of Psychology in the University of Wichita, prefaces his book by indicating that its "chief aim ... is to introduce the student to the facts and existing theories ordinarily subsumed under the category of abnormal psychology or psychopathology'.

The undergraduate will find that this volume is not a substitute for the several established introductory texts to psychiatry. Clinical descriptions of the various syndromes are brief and entirely inadequate for his needs, and on occasions are misleading. For instance, status epilepticus is briefly dismissed as follows: 'In advanced cases of arteriosclerosis in the senile, the degenerative changes in the blood vessels of the brain can erupt continually, bringing about status epilepticus in which one major attack follows another with little or no intermission. Eventually, the patient is killed off in one of the attacks of the chronic condition'. More space is given to some case histories than these would seem to warrant in terms of the contribution they make to the author's arguments. With regard to style, some readers will find that the rather chatty form of presentation soon becomes tedious. The term 'et cetera' is frequently employed-this term should have no place in any medical text book.

Professor Pronko does not confine himself to the more traditional and established doctrines of psychopathology but, incorporating less widely accepted theories, considers and evaluates conflicting viewpoints side-by-side. Whilst there is no attempt at systematically covering a field, this book's chief merit lies in the stimulus it will provide for discussion, particularly for postgraduate students.

\section{The Normal and Abnormal Unipolar Electro- cardiogram in Infants and Children}

Richard H. Wasserburger, M.D. Pp. ix + I 544, illustrated. Baltimore: Williams \& Wilkins. London: Baillière, Tindall \& Cox. 1963. $76 s$.

This book is sub-titled 'An analysis of the normal
QRS complex morphology and ventricular activation times' which indicates at once the limitations of the volume inasmuch as there is no discussion of the ST segment or $\mathrm{T}$ wave, or of arrhythmias. But even with these restrictions this study is a most valuable one starting as it does with a detailed analysis of the electrocardiograms of 1,150 normal infants and children. The data from this analysis are presented in graphic form and indicate the QRS configurations found in each lead at different ages together with the numerical values for the various deflections. This is a very good method of presentation and superior to the usual tedious tables of figures.

The second part of the book is concerned with the abnormal electrocardiogram and contains a thorough inquiry into the features of ventricular hypertrophy which is followed by discussions on some of the main congenital lesions of the heart and great vessels. In this section the $S T$ segment and $T$ waves are referred to.

Although it is not comprehensive this book will be indispensable to all those who are interested in pædiatric cardiology.

\section{Lectures on Experimental Gerontology}

F. Verzar, m.D. Pp. xvi + r28, illustrated. Springfield: Illinois. Charles C Thomas. I963. $\$ 5.75$.

Professor Verzar is known not only as a distinguished physiologist, but also as the founder of one of the first university departments in the world for the experimental study of ageing. In this book are printed a series of lectures which he gave in Basel, to the faculty of medicine, in 1961 .

Most of what is known of the effects of age on biological processes has hitherto been distributed among many different sciences, physiology, biochemistry, psychology, neurology, and others. In these lectures this scattered information is drawn together, organized and interpreted, much of it in the light of experiments conducted in the author's own laboratory.

The first few lectures are concerned with the methods of gerontological research, and show how complex is the process of ageing, and how it differs in various organisms. Methods of estimating the life span are discussed as well as the problems which arise from intercurrent illness and accidents. For example in nature the life span of some wild singing birds is about a year, but in captivity where accidents can be eliminated, it is about twenty years. Ageing may be considered as a process in which the organism gradually loses the power to adapt to its environment, and requires an increasing degree of protection for its survival. By exposing animals of different ages to cold, heat, and hypexia, Professor Verzar shows how this process can be studied in the laboratory.

The greater part of the book, however, is devoted to detailed studies of measurable age changes in collagen, muscle, nervous tissue, and sense organs. The final chapter looks to the future and suggests that at cellular level the ageing process may depend on changes in the DNA of the nucleus skin to those which can already be observed in collagen, since both have an apparently similar helical structure.

This book is translated from the German, but so well (the translator is the author's wife) that no-one would suspect it. It gives a most readable account of the physiology of ageing, and provides a most useful springboard for further advances in the future.

The increase in human life expectancy has already led to enormous social changes all over the world, and 
what may follow if we become able to control and to retard the process of ageing beggars the imagination.

\section{Salicylates}

An International Symposium sponsored by the Empire Rheumatism Council. Edited by A. ST.J. Dixon, B. K. Martin, M. J. H. Smith and P. H. N. WooD. Pp. xv + 3 ro, illustrated. London: J. \&. A. Churchill. 1963. 45 s.

This is a report of the proceedings of an International Symposium on Salicylates held at the Postgraduate Medical School, London, in September, 1962, which was designed to bring together clinicians and those engaged in research in this limited but important field. It consists of more than 40 papers contributed by active workers in different scientific disciplines from the U.K., the U.S.A., and the Continent. There were five sessions devoted to the distribution of Salicylates in the body; the effects of Salicylates on metabolism, epithelial surfaces and inflammation; and the toxicity of Salicylates. Following every second or third paper there is a brief summary of the subsequent discussions which are well edited and which greatly enhance the value of the book.

Like all such Symposia the value of individual contributions, some of which are highly technical, will depend on the background of the reader but there is much of interest for the biochemist, pharmacologist, clinician and those engaged in the pharmaceutical industry.

The clinical uses of Salicylates were not discussed directly, though frequently referred to, but the practising physician will find much useful information on the intriguing problem of gastro-intestinal hæmorrhage. There is a valuable paper by Winters on acid-base disturbances of salicylate intoxication in childhood, a possible omission in the symposium being the absence of a similar account of toxic effects in the adult. This is followed by a paper on the use of the artificial kidney in salicylate poisoning by Parsons and again one would comment on the absence of an authoritative account of alternative methods of treatment, with particular reference to forced alkaline diuresis.

This book should be seen by all rheumatologists, pædiatricians and physicians who prescribe large doses of these drugs, and it should prove to be a valuable starting point for anyone contemplating research on any aspect of Salicylates; he might find it had already been done.

\section{Partial Gastrectomy, Complications and Meta- bolic Consequences}

Edited by Prof. F. A. R. Stammers and J. A. Williams. Pp. ix +309 , illustrated. London: Butterworths. 1963. f4.

So long as surgeons are committed to removing more than half a man's stomach to treat a small mucosal defect farther down the alimentary tract so long will they benefit from reading this small book. They will find nothing in it about the technical steps of the operation but enough about the morbidity to make them pause for thought; it is estimated for instance that taking the country as a whole some 2,300 patients annually are, for one reason or another, disappointed with their gastrectomies. These reasons are dealt with in turn, beginning with Professor Stammers' excellent account of the mechanical complications of the operation and continuing with Mr. Williams' equally good account of the surgical physiology of the stomach. From here on the book is more suitable for postgraduate rather than undergraduate readers for it deals, often in some detail, with the effect of operations on both the gasfic and jejunal mucosæ, postgastrectomy anæmia, bब్ disease and malabsorption.

Minor features which are to be welcomed are the giving of references in full, the consistent use of the metric system and the commendable absence of misprints (apart from the use of the adjectival formoof 'mucus' when the predicative spelling is indicated). The writing, the figures and the photographs are clear-indeed the writing is so clear as to render figures 45 and 46 and Table II superfluous, but it is doubthtl whether their omission in the next edition would mate much difference to the price, which is $£ 4$.

Gastroenterology affords an excellent meeting grou for surgeons and physicians and the dyspeptic citizens of Birmingham should count themselves fortunate having such an harmonious and enquiring team avalable for their guidance; now that they have published tois book it is to be hoped that the benefits resulting from this collaboration will spread much farther afield.

\section{Modern Trends in Immunology}

Edited by Robert Cruickshank. Pp. vii $+{ }_{2} ?_{3}$, illustrated. London: Butterworths. 1963. $65 \mathrm{~s} .-$

This is an excellent volume which brings together the wide variety of techniques and concepts of immunolsy which has become a field incorporating many disciplines varying from genetics to protein chemistry. OTFAe reader will find authoritative essays on recent developments in immunology and especially valuable at the critical summaries of what has been learned from individual techniques, the extent of their limitations and to what use will they be put in the future.

The specific subjects covered are antigens, aromibodies and their reactions, natural and acquired imnofnity, immunization, hypersensitivity, autoimmunity and transplantation. This book succeeds in presenting ₹o the non-specialists reader the modern trends of this rapidly-developing subject.

It is well produced and clearly illustrated.

\section{The Development of the Brain and its Disturbange} by Harmful Factors

B. N. KLosovskir. Translated from the Russian by Basil Haigh. Pp. xiii +275 , illustrated. Oxford. London, New York and Paris: Pergamon Press. 1963. 70s.

The outstanding merit of this book is its lucid expression of fundamental facts about the developmentsof the brain. Its recapitulation of the essentials of embyyology which we have long forgotten is a masterpieceof clarity and brevity.

The account of the author's own studies of childforn whose brains have been damaged by a variety of noxious agents is full of interesting information. Some cauton about the conclusions is however necessary as author does not seem to be aware of the problems of observer-error and bias and the need for controls when assessing performance in children.

The book will be of great value to pædiatricians and neurologists and can be recommended. 